\title{
Peter Sharratt, Bernard Salomon, illustrateur lyonnais
}

\section{Michele Mastroianni}

\section{(2) OpenEdition}

\section{Journals}

\section{Edizione digitale}

URL: http://journals.openedition.org/studifrancesi/27436

DOI: 10.4000/studifrancesi.27436

ISSN: 2421-5856

\section{Editore}

Rosenberg \& Sellier

\section{Edizione cartacea}

Data di pubblicazione: 31 décembre 2006

Paginazione: 593

ISSN: 0039-2944

Notizia bibliografica digitale

Michele Mastroianni, «Peter Sharratt, Bernard Salomon, illustrateur lyonnais », Studi Francesi [Online], 150 (L | III) | 2006, online dal 30 novembre 2015, consultato il 08 novembre 2020. URL : http:// journals.openedition.org/studifrancesi/27436; DOI : https://doi.org/10.4000/studifrancesi.27436

\section{Questo documento è stato generato automaticamente il 8 novembre 2020.}

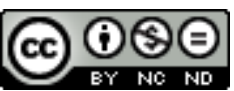

Studi Francesi è distribuita con Licenza Creative Commons Attribuzione - Non commerciale - Non opere derivate 4.0 Internazionale. 


\title{
Peter Sharratt, Bernard Salomon, illustrateur lyonnais
}

\author{
Michele Mastroianni
}

\section{NOTIZIA}

PETER SHARRATT, Bernard Salomon, illustrateur lyonnais, Genève, Droz («Travaux

d'Humanisme et Renaissance», CD), 2005, pp. 534.

1 Bernard Salomon, tra i più grandi incisori lionesi del Cinquecento, ha lavorato essenzialmente come illustratore di libri. In quanto tale ha riscosso gli apprezzamenti e le lodi dei maggiori editori di Lione, fra cui Jean de Tournes, che lo qualificava «Peintre autant excellent qu'il y en ayt point en nostre Hemisphere». Ai nostri giorni, un grande specialista dell'illustrazione libraria cinquecentesca, Hans-Joachim Trautner (Ovidausgaben von Jean I. und Jean II. de Tournes, 1978), lo definisce il migliore incisore e artista grafico lionese in assoluto. P. Sharratt offre una monografia importante ed esauriente su Salomon che interessa non soltantanto lo storico dell'arte e il biblioteconomo, ma anche lo studioso di letteratura per i contatti che questa disciplina può avere con l'iconologia. Illustratore, infatti, della Bibbia e della Metamorfosi di Ovidio, Salomon ha anche rilevanza per l'emblematica, in quanto uno stretto rapporto con la tradizione dell'emblema si riconosce nell'approccio moralizzante all'icona da parte dell'illustratore.

2 Nella prima sezione l'A. ricostruisce la biografia di Salomon, nel quadro dell'attività libraria lionese, documentando l'attività dell'artista sia come disegnatore che come incisore. Una seconda sezione offre la descrizione delle incisioni, classificate per ordine di genere, e precisamente stabilendo una prima categoria contenente i libri di emblemi, i libri scientifici e le opere letterarie classiche e in lingua volgare, una seconda categoria contenente le Entrées royales, una terza contenente una repertoriazione delle illustrazioni per la Bibbia e per le Metamorfosi ovidiane. In questa rassegna una particolare attenzione viene rivolta allo studio delle fonti e dell'utilizzazione che 
Salomon fa di queste stesse fonti. Una terza sezione tratta dello stile di Salomon, e dell'influsso che altri artisti hanno esercitato su di lui. Una quarta sezione, infine, particolarmente importante per lo studioso della letteratura, tratta dei rapporti fra testo e immagine. Completa il lavoro un catalogo ragionato di tutte le opere che possono essere attribuite a Salomon. Ricca la bibliografia. 